\title{
PHYSICAL PROPERTIES OF DOUGH FOR COOKIES WITH CHESTNUT FLOUR
}

Ljubica Dokić $^{1}$, Ivana Nikolić ${ }^{1}$, Dragana Šoronja-Simović ${ }^{1}$, Zita Šereš ${ }^{1}$, Veljko Krstonošic ${ }^{2}$, Aleksandar Fišteš ${ }^{1}$

\author{
${ }^{1}$ University of Novi Sad, Faculty of Technology, Bulevar cara Lazara 1, Novi Sad, Serbia \\ ${ }^{2}$ University of Novi Sad, Faculty of Medicine, Department of Pharmacy, Hajduk Veljkova 3, \\ Novi Sad, Serbia \\ ivananikolic@tf.uns.ac.rs
}

\begin{abstract}
A challenge for food producers is certainly to find suitable flour that can replace wheat flour in the production of flour-based products. Chestnut flour can be adequate substitute for wheat flour in the production of gluten-free flour confectionary products, due to high starch and sugar content. The objective of this work was to characterize physical changes, rheological and textural properties of dough for cookies with chestnut flour. The control dough was only with wheat flour. The substitution of wheat flour with chestnut flour for examined dough samples was at three different levels $(20,40$ and $60 \%$ ). Moisture of the dough was $22 \%$.

Dynamic oscillatory measurements describe all dough samples as typical viscoelastic systems with dominant elastic modulus $G^{\prime}$ over viscous modulus $G^{\prime \prime}$. The modulus ratio ( $\left.\tan \delta=G^{\prime \prime} / G^{\prime}\right)$ decreased with increase in amount of chestnut flour. Also, the dough compliance $(\mathrm{J})$ determined by creep and recovery curves decreased, thus more chestnut flour resulted in more brittle consistency of the dough. Texture determination confirmed the rheological results. Resistance to extension of the control dough sample was the highest, as well as dough extensibility. Application of chestnut flour and increase in its amount reduced these texture parameters for dough samples. Optimal physical properties of dough were achieved with low amounts of chestnut flour of $20 \%$.
\end{abstract}

Keywords: chestnut flour, cookies dough, rheology, texture

\section{INTRODUCTION}

Inadequate and unbalanced diet is one of the most important problems of modern life. The intake of functional food products is a way to reduce or eliminate the effects of inadequate diet. Functional food is any food, modified food or food component, which exhibits positive physiological effect on the human health and contributes to reduced risk of disease. Functional food meets the nutritional and health needs of the consumer and does not have any negative side effects. Positive effects of functional food are difficult to observe in the short term, because they are measurable only after a long period of consummation (Miletić et al. 2008).

There are many food products that can be classified as a functional food in the daily diet. Natural functional food product may be plant food (fruit, vegetables, grains and nuts), animal products (dairy products, fish, beef) and some drinks (tea, red wine). Confectionary products may represent a functional food, due to addition of certain functional components such as vitamins, minerals, antioxidants, prebiotics, probiotics, or dietary fiber (Gibson and Williams 2000).

Chestnut is characteristic by its low sodium content and it is recommended in the diet of people with kidney and cardiovascular diseases. Also it has significant positive effect in the treatment of inflammation of the blood vessels and veins. Chestnut is suitable in the diet for 
patients with rheumatic diseases and celiac disease (Demirkesen et al. 2010). Researches that are related to the replacement of wheat flour in the confectionery products with flour of other cereals, which do not contain gluten, indicated that rice and chestnut flours in proper relation are suitable tailor made mixture of flour for production of gluten-free flour based confectionery products with satisfactory quality. Chestnut flour can be adequate substitute for wheat flour in the production of gluten-free flour confectionary products, due to high starch and sugar content (Demirkesen et al. 2011).

The objective of this work was to characterize physical changes, rheological and textural properties of dough for cookies with chestnut flour. The control dough was only with wheat flour. The substitution of wheat flour with chestnut flour for examined dough samples was at three different levels (20, 40 and 60\%). Moisture of the dough was $22 \%$.

\section{MATERIAL AND METHODS}

\section{Material}

Materials used for experimental work were wheat flour for flour based confectionary products (Type 500), chestnut flour ("Molino Rosseto", Italy), sugar powder, vegetable fat, $\mathrm{NH}_{4} \mathrm{HCO}_{3}, \mathrm{NaHCO}_{3}, \mathrm{NaCl}$ and water. The compositions of the flours are presented in Table 1.

Table 1 Composition of the wheat and chestnut flour

\begin{tabular}{|l|c|c|}
\hline $\begin{array}{c}\text { Components } \\
\text { of the flours }\end{array}$ & Wheat flour (\%) & Chestnut flour (\%) \\
\hline Moisture & 12.29 & 5.71 \\
\hline Starch & 73.75 & 45.28 \\
\hline Proteins & 9.70 & 5.54 \\
\hline Reducing sugars & 1.83 & 21.10 \\
\hline Fats & 0.84 & 3.19 \\
\hline Ash & 0.45 & 2.06 \\
\hline
\end{tabular}

\section{Methods}

\section{Preparation of the dough for cookies}

The dough for cookies was prepared by baking test method. The mass of obtained dough was $350 \mathrm{~g}$. Ingredients for the dough were flour $(199.4 \mathrm{~g})$, sugar powder $(69.8 \mathrm{~g})$, vegetable fat $(41.9 \mathrm{~g}), \mathrm{NaCl}(1.1 \mathrm{~g}), \mathrm{NaHCO}_{3}(0.6 \mathrm{~g}), \mathrm{NH}_{4} \mathrm{HCO}_{3}(0.4 \mathrm{~g})$ and water. The amount of water was added to achieve $22 \%$ of dough moisture. The control sample contained wheat flour. Wheat flour was substituted with chestnut flour in amounts 20,40 and $60 \%$ for samples with chestnut flour. The ingredients were mixed in Z profiled mixer (ZD2245, Stephan-Werke Hamelin) for 15 minutes. Dough was pressed manually in a shape of a compact low cylinder. After $2 \mathrm{~min}$ of the relaxation the dough stripe was developed by pressing dough twice in either direction between two rollers of the laminator (Laminoir Marchand LA4-500). First lamination was with $10 \mathrm{~mm}$ gap and second one was with $6 \mathrm{~mm}$ gap. Dough relaxed for 0.5 min after each lamination.

\section{Dough quality determination \\ Rheological determination}

The quality of dough for cookies was defined by determination of rheological parameters (viscoselastic properties, resistance to applied stress and recover ability) and textural properties of the dough (resistance to extension and dough extensibility). 
Rheological measurements were performed by rotational viscometer HAAKE RheoStress RS600 (Thermo Electron Corporation, Karlsruhe, Germany) with plate-plate sensor PP60 Ti (plate diameter was $60 \mathrm{~mm}$ and gap $1 \mathrm{~mm}$ ). Viscoelastic properties of the dough were determined by measurements of storage (G') modulus and loss (G') modulus and their ratio $\tan \delta=\mathrm{G}^{\prime} / \mathrm{G}$ '. The measurements were performed in linear viscoelastic regime (LVE) at $30 \mathrm{~Pa}$, where the moduli were observed with increase of frequency from 1 to $10 \mathrm{~Hz}$.

Viscoelastic response of the samples at constant stress, as well as their behavior after removing the stress, were determined by creep and recovery test. The test was performed in the LVE regime in which the deformation amplitude was proportional to applied stress amplitude. The creep time with constant stress $(\sigma=30 \mathrm{~Pa})$ was $150 \mathrm{~s}$ and the recovery period after removing the stress was $300 \mathrm{~s}$. Creep data, collected under constant stress $(\sigma)$ over time $(\mathrm{t})$, can be described by a creep compliance $(J)$ function, in terms of shear deformation $(\gamma)$, using equation $\mathrm{J}(\mathrm{t})=\gamma(\mathrm{t}) / \sigma$. The creep data were analyzed by Burger's model presented by equation $\mathrm{J}(\mathrm{t})=\mathrm{J}_{0}+\mathrm{J}_{1} \cdot(1-\exp (-\mathrm{t} / \lambda))+\mathrm{t} / \eta_{0}$. For the recovery phase the equation of the Burger's model is $\mathrm{J}(\mathrm{t})=\mathrm{J}_{\max }-\mathrm{J}_{0}-\mathrm{J}_{1} \cdot(1-\exp (-\mathrm{t} / \lambda))$. The value $\mathrm{J}_{0}$ is the instantaneous compliance, $\mathrm{J}_{1}$ is retarded (viscoelastic) compliance, $\mathrm{J}_{\max }$ is maximum compliance, $\lambda$ is mean retardation time and $\eta_{0}$ is Newtonian viscosity (Vithanage et al. 2009; Sozer 2009; Steffe 1996).

\section{Textural determination}

Texture determination of the dough by Kieffer dough \& gluten extensibility method (Sams, 1999) was performed using Texture Analyser TA.HD Plus (Stable Micro Systems, Surrey, UK). After preparation of the dough, the samples were extended to the elastic limit and to the point of breaking.

The load cell of $5 \mathrm{~kg}$ was applied and the measurement parameters were pretest speed of 2 $\mathrm{mm} / \mathrm{s}$, test speed of $3.3 \mathrm{~mm} / \mathrm{s}$ and post test speed of $10 \mathrm{~mm} / \mathrm{s}$.

\section{RESULTS AND DISCUSSION}

\section{Rheological properties}

Viscoelastic properties of the dough are very significant because of their influence on the dough properties during the production and on the quality of the final product. The changes of viscoelastic modulus of the dough with increase in frequency are presented on Fig. 1 .

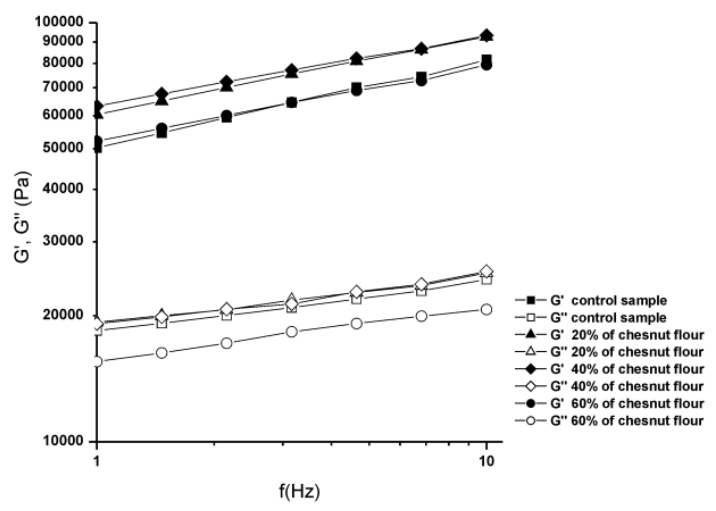

Figure 1 Storage (G') and loss (G”) modulus for dough samples 
For all dough samples, regardless of the presence or of the amount of chestnut flour, the domination of storage modulus (G') over loss (G”) modulus was observed. That is characteristic for the structure of the dough, which is typical viscoelastic system (Korus et al. 2009).

Viscoelastic parameter, $\tan \delta$, which indicates the contribution of elastic and viscous components of the dough, was less than 1 for all samples. That was conformation that the dough samples were viscoelastic systems with dominant elastic component. Increase in the amount of chestnut flour reduced the values of $\tan \delta$ (Table 2), which pointed to higher domination of storage modulus over loss modulus and to harder dough consistency.

Table 2 The values of $\tan \delta$ for dough samples

\begin{tabular}{|l|c|}
\hline \multicolumn{1}{|c|}{ Dough sample } & $\tan \delta=\mathrm{G}^{\prime} / \mathrm{G}^{\prime}$ \\
\hline Control sample & 0.324 \\
\hline $20 \%$ of chestnut flour & 0.289 \\
\hline $40 \%$ of chestnut flour & 0.282 \\
\hline $60 \%$ of chestnut flour & 0.280 \\
\hline
\end{tabular}

Creep and recovery curves describe the characteristic viscoelastic behavior of dough, with partial ability to recover the previous structure after removing the stress. The influence of chestnut flour on viscoelastic behavior of the dough samples is presented on Fig. 2. Compared to control sample the compliance for all dough samples with chestnut flour decreased. Also, increase in amount of the chestnut flour reduced the compliance of the samples.

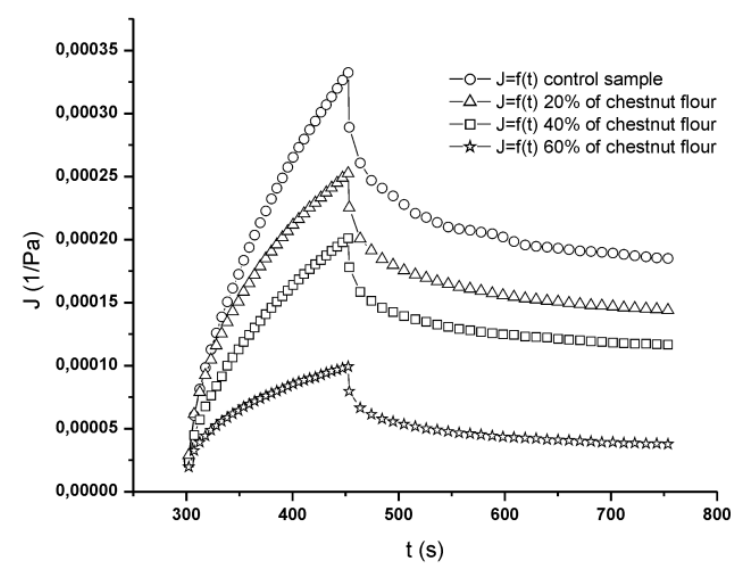

Figure 2 Creep and recovery curves for the dough samples

The values of parameters from the creep and recovery curves defined by Burger's model are presented in Table 3. 
Table 3 The parameters of Burger's model

\begin{tabular}{|l|c|c|c|c|c|}
\hline \multicolumn{7}{|c|}{ Creep phase } \\
\hline \multicolumn{1}{|c|}{ Sample } & $\mathrm{J}_{0}\left(\mathrm{~Pa}^{-1}\right)$ & $\mathrm{J}_{1}\left(\mathrm{~Pa}^{-1}\right)$ & $\eta_{0}(\mathrm{Pas})$ & $\lambda_{1}(\mathrm{~s})$ & $\mathrm{J}_{\max }\left(\mathrm{Pa}^{-1}\right)$ \\
\hline Control sample & $2.8 \cdot 10^{-5}$ & $11.2 \cdot 10^{-5}$ & $1.3 \cdot 10^{6}$ & 196.8 & $3.4 \cdot 10^{-4}$ \\
\hline $20 \%$ of chestnut flour & $2.7 \cdot 10^{-5}$ & $7.4 \cdot 10^{-5}$ & $2.0 \cdot 10^{6}$ & 196.8 & $2.2 \cdot 10^{-4}$ \\
\hline $40 \%$ of chestnut flour & $2.7 \cdot 10^{-5}$ & $6.7 \cdot 10^{-5}$ & $2.2 \cdot 10^{6}$ & 196.8 & $2.0 \cdot 10^{-4}$ \\
\hline $60 \%$ of chestnut flour & $1.9 \cdot 10^{-5}$ & $3.3 \cdot 10^{-5}$ & $4.6 \cdot 10^{6}$ & 196.7 & $1.0 \cdot 10^{-4}$ \\
\hline \multicolumn{6}{|c|}{ Recovery phase } \\
\hline Control sample & $3.2 \cdot 10^{-4}$ & $7.1 \cdot 10^{-5}$ & $3.5 \cdot 10^{6}$ & 327.7 & $/$ \\
\hline $20 \%$ of chestnut flour & $2.0 \cdot 10^{-4}$ & $4.4 \cdot 10^{-5}$ & $5.7 \cdot 10^{6}$ & 327.7 & $/$ \\
\hline $40 \%$ of chestnut flour & $1.8 \cdot 10^{-4}$ & $3.7 \cdot 10^{-5}$ & $6.6 \cdot 10^{6}$ & 327.7 & $/$ \\
\hline $60 \%$ of chestnut flour & $0.8 \cdot 10^{-4}$ & $1.2 \cdot 10^{-5}$ & $20 \cdot 10^{6}$ & 327.6 & $/$ \\
\hline
\end{tabular}

The values for all compliances $\left(\mathrm{J}_{0}, \mathrm{~J}_{1}\right.$ and $\left.\mathrm{J}_{\max }\right)$ for observed samples were reduced with increase in amount of chestnut flour. The instantaneous compliance for creep phase was reduced in the range for $3.57-32.14 \%$ by addition of chestnut flour and by increase in amount of the flour, and the viscoelastic compliance in the range for $32.73-70 \%$. During instantaneous compliance bonds stretch elastically when stress is applied and recover instantaneously when stress is removed, whereas in viscoelastic compliance bonds break and reform in different rates (Onyango et al. 2009). Maximum compliance decreased in a range for $35.29-70.88 \%$ with addition of chestnut flour and with increase in its amount, while the values of Newtonian viscosity $\left(\eta_{0}\right)$ increased.

Thus, all creep and recovery parameters pointed that addition of chestnut flour and the increase in its amount reduced the compliance of the dough, its extensibility and recovery ability.

\section{Textural properties}

During textural determination of the dough samples, the resistance to extension and extensibility of the dough were measured. Obtained values are presented in Table 4.

Table 4 The textural parameters of the dough samples

\begin{tabular}{|l|c|c|}
\hline \multicolumn{1}{|c|}{ Sample } & Extensibility $\pm \mathrm{SD}(\mathrm{mm})$ & Resistance to extension $\pm \mathrm{SD}(\mathrm{g})$ \\
\hline Control sample & $8.01 \pm 0.72$ & $15.58 \pm 0.53$ \\
\hline $20 \%$ of chestnut flour & $6.22 \pm 1.1$ & $14.32 \pm 1.55$ \\
\hline $40 \%$ of chestnut flour & $4.15 \pm 1.07$ & $10.05 \pm 1.34$ \\
\hline $60 \%$ of chestnut flour & $/$ & $/$ \\
\hline
\end{tabular}

The resistances to extension and dough extensibility are dependent of content and quality of the gluten. For all dough samples the addition of chestnut flour reduced these textural parameters of the dough compared to control sample, because of decrease of gluten content. Also, the textural parameters were reduced by increase in amount of chestnut flour. The dough extensibility decreased for approximately $25 \%$ by increase of chestnut flour for $20 \%$. The sample with $60 \%$ of chestnut flour could not be measured, because of the significant amount of chestnut flour and poorly developed gluten network.

These results are in accordance with rheological determination of the samples. Textural parameters confirmed the fact that gradual substitution of wheat flour with chestnut flour caused the increase in hardness of dough consistency and reduced the flexibility of the dough. Less gluten content in the structure of dough samples with chestnut flour caused decrease in 
degree of association. Also significant content of sucrose in chestnut flour amplified the sucrose-starch interaction that resulted in brittle consistency of the dough with chestnut flour. Optimal physical properties of dough were achieved with low amounts of chestnut flour of $20 \%$.

\section{ACKNOWLEDGEMENTS}

This work was done within Project "Cookies and crackers with functional characteristics aimed for consumers with special dietary needs" financed by the Provincial Secretariat for Science and Technological Development of the Government of Autonomous Province of Vojvodina, Republic of Serbia.

\section{REFERENCES}

Demirkesen, I., Mert, B., Sumnu, G., Sahin, S. (2010). Utilization of chestnut flour in glutenfree bread formulations. Journal of Food Engineering, 101, 329-336.

Demirkesen, I., Sumnu, G., Sahin, S. (2011). Utilization of chestnut flour in gluten-free cakes, Proceedings of the 6th CIGR Section VI International Symposium "Towards a Sustainable Food Chain" Food Process, Bioprocessing and Food Quality Management Nantes, France.

Gibson, G.R., Williams, C.M. (2000). Functional foods: concept to product. Pp. 259-287. Cambridge, Woodhead Publishing Limited.

Korus, J., Witczak, M., Ziobro, R., Juszczak, L. (2009). The impact of resistant starch on characteristics of gluten-free dough and bread. Food Hydrocolloids. 23, 988-995.

Miletić, I., Šobajić, S., Đorđević, B. (2008). Funkcionalna hrana-uloga u unapređivanju zdravlja. Journal of Medical Biochemistry, 27(3), 367-370.

Onyango, C, Unbehend, G, Lindhauer, M.G. (2009). Effect of cellulose-derivatives and emulsifiers on creep-recovery and crumb properties of gluten-free bread prepared from sorghum and gelatinised cassava starch. Food Research International. 42, 949-955.

Sozer, N. (2009). Rheological properties of rice pasta dough supplemented with proteins and gums. Food Hydrocolloids. 23, 849-855.

Steffe, F.J. (1996). Rheological methods in food process engineering 2nd ed. Still Valley, Freeman Press.

Vithanage, C.R., Grimson, M.J. Smith, B.G.(2009). The effect of temperature on the rheology of butter, a spreadable blend and spreads. Journal of Texture Studies. 40, 346-369. 